\title{
Study of Stability Analysis for a Class of Fourth Order Boundary Value Problems
}

\author{
C. Bala Rama Krishna1, P. S. Rama Chandra Rao² \\ ${ }^{1}$ Department of Mathematics, Chaitanya Degree College (Autonomous), Warangal, India \\ ${ }^{2}$ Department of Mathematics, Kakatiya Institute of Technology \& Science, Warangal, India \\ Email: cbrk2004@gmail.com, patibanda20@yahoo.co.in
}

Received 16 April 2014; revised 28 May 2014; accepted 8 June 2014

Copyright (C) 2014 by authors and Scientific Research Publishing Inc.

This work is licensed under the Creative Commons Attribution International License (CC BY). http://creativecommons.org/licenses/by/4.0/

(c) (i) Open Access

\begin{abstract}
Fourth order differential equations are considered to develop the class of methods for the numerical solution of boundary value problems. In this paper, we have discussed the regions of absolute stability of fourth order boundary value problems. Methods proposed and derived in this paper are applied to solve a fourth-order boundary value problem. Numerical results are given to illustrate the efficiency of our methods and compared with exact solution.
\end{abstract}

\section{Keywords}

Numerical Differentiation, Initial Value Problem, Boundary Value Problem, Absolute Stability, Multistep Methods

\section{Introduction}

The determination process for the numerical solution of initial value problems in ordinary differential equations can be classified into two categories-single step methods and multistep methods. Single step methods are those in which the approximation for the point $x=x_{n+1}$ involves information from only one of the previous points $x=x_{n}$. Methods using the approximation at more than one previous points to determine the approximation at the next point are called multistep methods. Thus a $k$-step method requires information about the solution at $k$ points $x_{n}, x_{n-1}, \cdots, x_{n-k+1}$ to compute the solution at the point $x_{n+1}$. Finite difference methods for boundary value problems are discussed in [1]. Linear multi step methods of second order differential equations are discussed in [2]. The methods based on numerical differentiation for first-order differential equations have been shown to be stiffly stable by Gear [3]. A detailed study of the single step and multistep methods has been carried out by Gear [3], Gragg and Statter [4] and Henrici [5]. Gear [3] and Peter Henrici [5] have derived special multistep methods based on numerical integration and numerical differentiation for solving first-order differential equations. Jain [6] 
has considered high order stiffly stable methods. Further information can be had from [7] and [8]. Special multistep methods based on numerical differentiation for solving the initial value problem have been derived in Rama Chandra Rao [9]. The methods now to be discussed are based on replacing the function $f(x, y(x))$ which is unknown, by an interpolating polynomial having the values $f_{n}=f\left(x_{n}, y_{n}\right)$ on a set of points $x_{n}$ where $y_{n}$ has already been computed. The methods discussed in this paper are essentially based on the idea that the solution is best approximated by polynomials. The motivation for the work carried out in this paper arises from the methods based on numerical differentiation for the first-order differential equations, special multistep methods based on numerical integration for the solution of the special second-order differential equations by Henrici [5] and Special multistep methods based on numerical differentiation for solving the initial value problem by Rama Chandra Rao [9]. In Henrici [5] methods based on Numerical Integration have been derived by integrating $y^{\prime \prime}=f(x, y)$ twice and replacing the function $f(x, y)$ by an interpolating polynomial. Special multistep methods have been derived by replacing $y(x)$ on the left hand side of $y^{i v}(x)=f(x, y)$ by an interpolating polynomial and differentiating it four times. We have investigated a class of implicit methods. It is found that the implicit methods have order $(k-3)$. Some local truncation errors are provided. The regions of absolute stability of the methods are derived. Numerical tests of the performance of the methods are established by solving differential equation and compared with the exact solution. The numerical results reported show the validity of our methods.

\section{General Linear Multistep Methods for Special Fourth-Order Differential Equations}

The special fourth order differential equation

$$
y^{i v}=f(x, y), y(0)=y_{0}, y^{\prime}(0)=y_{0}^{\prime}, \quad y^{\prime \prime}(0)=y_{0}^{\prime \prime}, \quad y^{\prime \prime \prime}(0)=y_{0}^{\prime \prime \prime}
$$

occurs frequently in many number of problems of science and engineering.

A general linear multistep method of step number $k$ for the numerical solution of equation (1) is given by

$$
y_{n+1}=\sum_{j=1}^{k} a_{j} y_{n+1-j}+h^{4} \sum_{j=0}^{k} b_{j} y_{n+1-j}
$$

where $a_{j}, b_{j}$ are constants and " $h$ " is the step length.

Introducing the polynomials

$$
\rho(\xi)=\xi^{k}-\sum_{j=1}^{k} a_{j} \xi^{k-1} \text { and } \sigma(\xi)=\sum_{j=1}^{k} b_{j} \xi^{k-1}
$$

Equation (2) can be written as

$$
\rho(E) y_{n-k+1}-h^{4} \sigma(E) y_{n-k+1}^{i v}=0
$$

In Equation (4), " $E$ " is the shift operator defined by $E\left(y_{n}\right)=y_{n+1}$

Applying (4) to $y^{i v}=\lambda y$, we get the characteristic equation

$$
\rho(\xi)-\bar{h} \sigma(\xi)=0 \text {, where } \bar{h}=\lambda h^{4}
$$

The roots $\xi_{i}$ of the characteristic Equation (5) and $\bar{h}$ are in general, complex and the region of absolute stability is defined to be the region of the complex $\bar{h}$-plane such that the roots of the characteristic Equation (5) lie within the unit circle whenever $\bar{h}$ lies in the interior of the region. Denoting the region of absolute stability of $R$ and its boundary by $\partial R$, the locus of $\partial R$ is given by

$$
\bar{h}(\theta)=\rho\left(\mathrm{e}^{i \theta}\right) / \sigma\left(\mathrm{e}^{\mathrm{i} \theta}\right), 0 \leq \theta \leq 2 \pi
$$

\section{Derivation of the Methods}

Let $p(x)$ be the backward difference interpolating polynomial of $y(x)$ at $(k+1)$ abscissas $x_{n+1}, x_{n}, \cdots, x_{n-k+1}$. Then $p(x)$ is given by

$$
p(x)=\sum_{m=0}^{k}(-1)^{m}\left(\begin{array}{c}
-s \\
m
\end{array}\right) \nabla^{m} y_{n+1}, \quad s=\frac{\left(x-x_{n+1}\right)}{h}
$$


Differentiating (7) four times with respect to $x$, we get

$$
p^{i v}(x)=\left(\frac{1}{h^{4}}\right) \sum_{m=0}^{k} \frac{\mathrm{d}^{4}}{\mathrm{ds} s^{4}}\left[\left(-1^{m}\right)\left(\begin{array}{c}
-s \\
m
\end{array}\right)\right] \nabla^{m} y_{n+1} .
$$

Replacing $y^{\text {iv }}(x)$ by $p^{\text {iv }}(x)$ in Equation (1) and putting $x=x_{n+1-r}$ i.e. $s=-r$, we get,

$$
\sum_{m=0}^{k} \delta_{r, m} \nabla^{m} y_{n+1}=h^{4} f_{n+1-r}
$$

where

$$
\delta_{r, m}=\frac{\mathrm{d}^{4}}{\mathrm{~d} s^{4}}\left[(-1)^{m}\left(\begin{array}{c}
-s \\
m
\end{array}\right)\right]
$$

Taking $r=0$ in (8), a class of methods can be attained which are given by

$$
\sum_{m=0}^{k} \delta_{0, m} \nabla^{m} y_{n+1}=h^{4} f_{n+1}
$$

The coefficients $\delta_{0, m}$ are shown in Table 1 .

Differences in (10) are expressed in terms of function values.

After simplification, the Equation (10) will turn out into the form

$$
\sum_{j=0}^{k} a_{j} y_{n+1-j}=h^{4} f_{n+1}
$$

The coefficients $a_{j}$ are shown in Table 2 .

The local truncation error of the formula (11) is given by

$$
L T E=\delta_{0, k+1} h^{k+1} y^{k+1}(\eta)
$$

\begin{tabular}{|c|c|c|c|c|c|c|c|c|c|c|}
\hline K & $\mathrm{J}$ & & & & & & & & & \\
\hline & 0 & 1 & 2 & 3 & 4 & 5 & 6 & 7 & 8 & 9 \\
\hline 4 & 1 & -4 & 6 & -4 & 1 & & & & & \\
\hline 5 & 3 & -14 & 26 & -24 & 11 & -2 & & & & \\
\hline \multirow{2}{*}{6} & 35 & -186 & 411 & -484 & 321 & -114 & $\underline{17}$ & & & \\
\hline & $\overline{6}$ & $\overline{6}$ & $\overline{6}$ & $\overline{6}$ & $\overline{6}$ & $\overline{6}$ & $\overline{6}$ & & & \\
\hline \multirow{2}{*}{7} & $\underline{56}$ & -333 & 852 & -1009 & 846 & -555 & 164 & -21 & & \\
\hline & $\overline{6}$ & $\overline{6}$ & $\overline{6}$ & 6 & $\overline{6}$ & $\overline{6}$ & $\overline{6}$ & $\overline{6}$ & & \\
\hline \multirow{2}{*}{8} & 3207 & -21056 & 61156 & -94512 & 101530 & -76352 & 33636 & -8576 & 967 & \\
\hline & $\overline{240}$ & 240 & $\overline{240}$ & $\overline{240}$ & 240 & $\overline{240}$ & $\overline{240}$ & $\overline{240}$ & $\overline{240}$ & \\
\hline \multirow{2}{*}{9} & $\underline{4275}$ & $\underline{-30668}$ & $\underline{99604}$ & -184224 & $\underline{236098}$ & -210920 & $\underline{123348}$ & -47024 & 10579 & -1068 \\
\hline & 240 & 240 & 240 & 240 & $\overline{240}$ & 240 & $\overline{240}$ & 240 & $\overline{240}$ & $\overline{240}$ \\
\hline
\end{tabular}

Table 1. Coefficients of $\delta_{0, m} ; m=0(1) 9$.

\begin{tabular}{cccccccccccc}
\hline $\mathrm{M}$ & 0 & 1 & 2 & 3 & 4 & 5 & 6 & 7 & 8 & 9 \\
\hline$\delta_{0, m}$ & 0 & 0 & 0 & 0 & 1 & 2 & $\frac{17}{6}$ & $\frac{7}{2}$ & $\frac{967}{240}$ & $\frac{4523}{945}$ \\
\hline
\end{tabular}

Table 2. Coefficients of $a_{j} ; j=0(1) k, k=4(1) 9$. 
It follows that the $k$-step method (14) has the order $k-3$, which is absolutely stable for $h \in[-4,0]$ For the method (13), we have

$$
\rho(\xi)=\sum_{j=0}^{k} a_{j} \xi^{k-j} \text { and } \sigma(\xi)=\xi^{k} .
$$

The regions of absolute stability of the method for $k=4,5,6,7,8$ and 9 are shown in Figure 1 and Figure 2 (Taking real part on $x$-axis and imaginary part on $y$-axis). The region of absolute stability is the region lying outside the boundary.

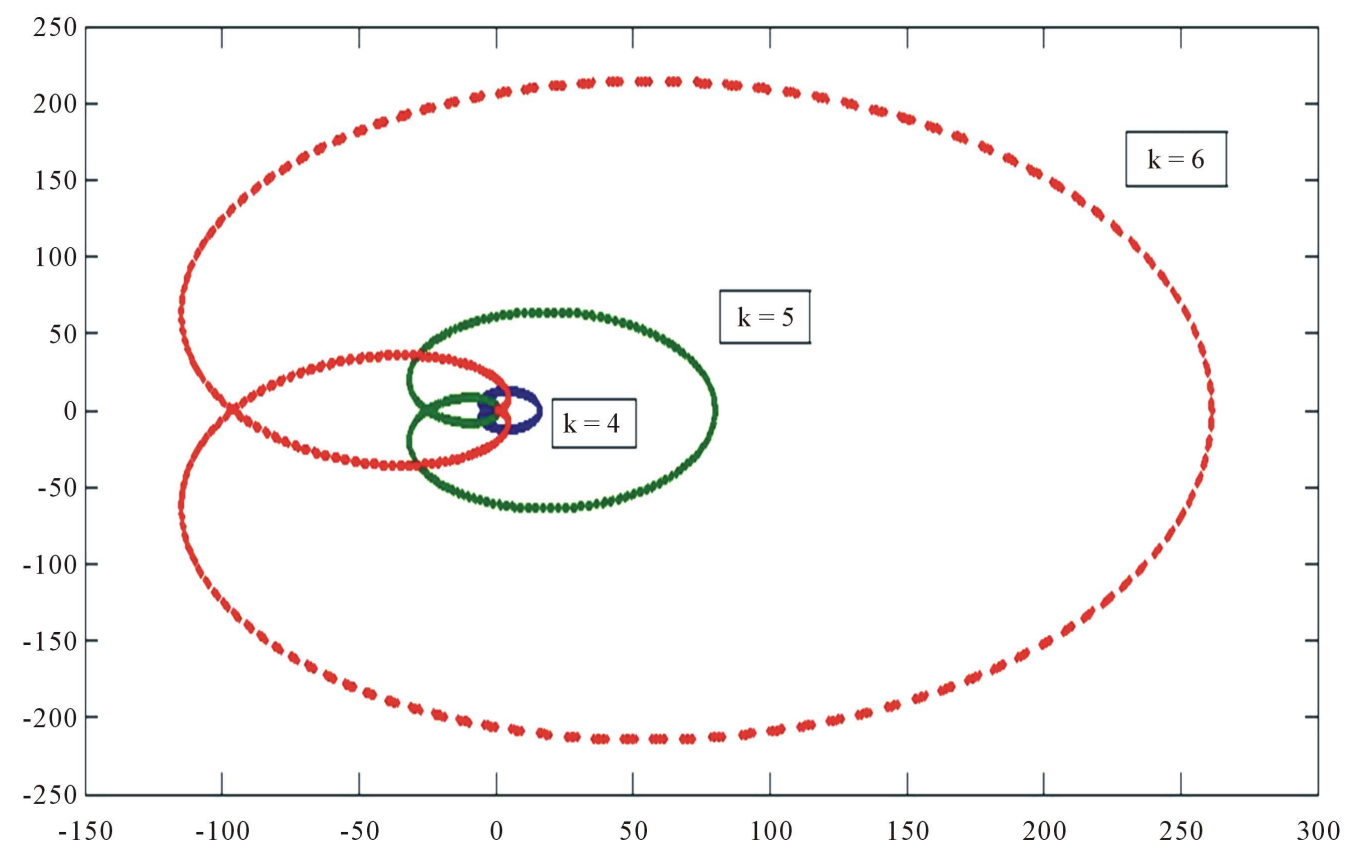

Figure 1. The region of absolute stability of the method (13) for $k=4,5$ and 6 .

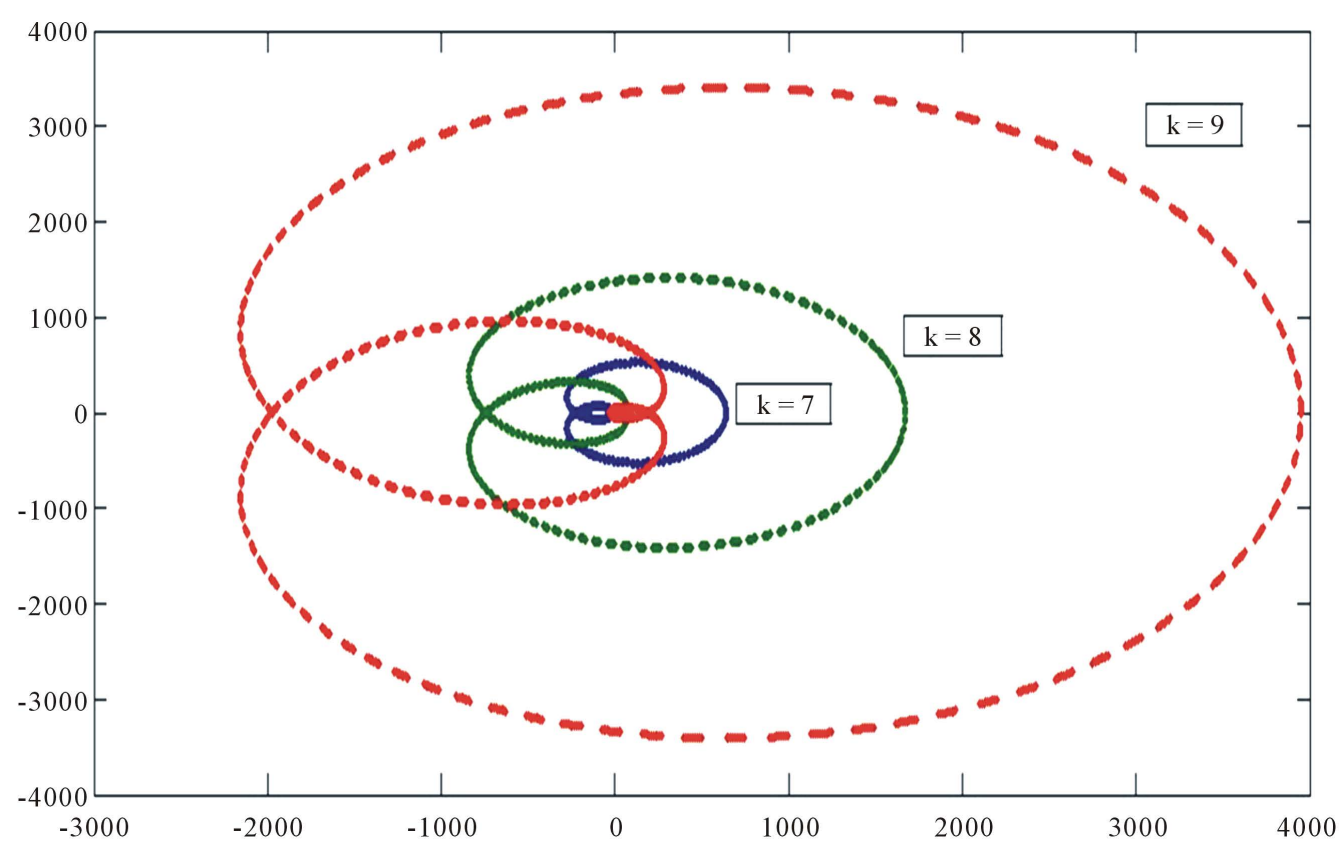

Figure 2. The region of absolute stability of the method (13) for $k=7,8$ and 9. 


\section{Numerical Example}

In this section, we have applied ND methods to solve the differential equation

$$
y^{i v}=y+\sin x, y(0)=0, y^{\prime}(0)=1, \quad y^{\prime \prime}(0)=-1, y^{\prime \prime \prime}(0)=0
$$

in the interval $[0,4]$ with $h=0.01$ and $h=0.02$ and the results are shown in Table 3 and Table 4.

The fourth order numerical differentiation method derived in this paper for $k=6$ is

$$
y_{n+1}=\frac{186}{35} y_{n}-\frac{411}{35} y_{n-1}+\frac{484}{35} y_{n-2}-\frac{321}{35} y_{n-3}+\frac{114}{35} y_{n-4}-\frac{17}{35} y_{n-5}+\frac{6}{35} h^{4} f_{n+1}
$$

\section{Discussion and Conclusion}

The methods based on numerical integration are found to be closed regions of absolute stability; the methods

\begin{tabular}{|c|c|c|c|}
\hline$X$ & Exact Solution & Numerical Solution by fifth order ND & Absolute Error \\
\hline 0.10 & $9.500016525794 \mathrm{E}-02$ & $9.500016525794 \mathrm{E}-02$ & $7.813194535800 \mathrm{E}-15$ \\
\hline 0.20 & $1.800052419090 \mathrm{E}-01$ & $1.800052419090 \mathrm{E}-01$ & $5.329070518201 \mathrm{E}-15$ \\
\hline 0.30 & $2.550394442682 \mathrm{E}-01$ & $2.550394442681 \mathrm{E}-01$ & $5.662137425588 \mathrm{E}-15$ \\
\hline 0.40 & $3.201646548346 \mathrm{E}-01$ & 3.201646548346E-01 & $3.719247132494 \mathrm{E}-15$ \\
\hline 0.50 & $3.754975976986 \mathrm{E}-01$ & $3.754975976986 \mathrm{E}-01$ & $3.774758283726 \mathrm{E}-15$ \\
\hline 0.60 & 4.212257271813E-01 & 4.212257271813E-01 & $2.775557561563 \mathrm{E}-15$ \\
\hline 0.70 & 4.576217499812E-01 & 4.576217499812E-01 & $2.720046410332 \mathrm{E}-15$ \\
\hline 0.80 & 4.850567100313E-01 & 4.850567100313E-01 & $8.881784197001 \mathrm{E}-16$ \\
\hline 0.90 & $5.040115785530 \mathrm{E}-01$ & $5.040115785530 \mathrm{E}-01$ & $1.221245327088 \mathrm{E}-15$ \\
\hline 1.00 & $5.150873072263 \mathrm{E}-01$ & $5.150873072263 \mathrm{E}-01$ & $2.997602166488 \mathrm{E}-15$ \\
\hline 1.10 & $5.190133197868 \mathrm{E}-01$ & $5.190133197868 \mathrm{E}-01$ & $1.887379141863 \mathrm{E}-15$ \\
\hline 1.20 & $5.166544364783 \mathrm{E}-01$ & $5.166544364783 \mathrm{E}-01$ & $4.662936703426 \mathrm{E}-15$ \\
\hline 1.30 & $5.090162464214 \mathrm{E}-01$ & $5.090162464214 \mathrm{E}-01$ & $5.440092820663 \mathrm{E}-15$ \\
\hline 1.40 & 4.972489648573E-01 & 4.972489648573E-01 & $5.440092820663 \mathrm{E}-15$ \\
\hline 1.50 & 4.826498351587E-01 & 4.826498351587E-01 & $8.826273045770 \mathrm{E}-15$ \\
\hline 1.60 & 4.666641592316E-01 & 4.666641592316E-01 & $9.992007221626 \mathrm{E}-15$ \\
\hline 1.70 & 4.508850642096E-01 & 4.508850642096E-01 & $1.304512053935 \mathrm{E}-14$ \\
\hline 1.80 & 4.370521379547E-01 & 4.370521379547E-01 & $1.637578961322 \mathrm{E}-14$ \\
\hline 1.90 & 4.270490905788E-01 & 4.270490905789E-01 & $1.471045507628 \mathrm{E}-14$ \\
\hline 2.00 & 4.229006237963E-01 & 4.229006237963E-01 & $1.737499033538 \mathrm{E}-14$ \\
\hline
\end{tabular}

Table 3. Solution by fifth order ND with $h=0.01$. 
Table 4. Solution by fifth order ND with $h=0.02$.

\begin{tabular}{|c|c|c|c|}
\hline$X$ & Exact Solution & Numerical Solution by fifth order ND & Absolute Error \\
\hline 0.10 & $9.500016525794 \mathrm{E}-02$ & $9.500016525718 \mathrm{E}-02$ & $7.650130529058 \mathrm{E}-13$ \\
\hline 0.20 & $1.800052419090 \mathrm{E}-01$ & $1.800052419082 \mathrm{E}-01$ & $7.430722703816 \mathrm{E}-13$ \\
\hline 0.30 & $2.550394442682 \mathrm{E}-01$ & $2.550394442675 \mathrm{E}-01$ & $6.964984144986 \mathrm{E}-13$ \\
\hline 0.40 & $3.201646548346 \mathrm{E}-01$ & $3.201646548340 \mathrm{E}-01$ & $6.305511668359 \mathrm{E}-13$ \\
\hline 0.50 & $3.754975976986 \mathrm{E}-01$ & $3.754975976981 \mathrm{E}-01$ & $5.463962615693 \mathrm{E}-13$ \\
\hline 0.60 & 4.212257271813E-01 & 4.212257271809E-01 & $4.425348976156 \mathrm{E}-13$ \\
\hline 0.70 & $4.576217499812 \mathrm{E}-01$ & 4.576217499809E-01 & $3.217981436876 \mathrm{E}-13$ \\
\hline 0.80 & 4.850567100313E-01 & $4.850567100311 \mathrm{E}-01$ & $1.886824030350 \mathrm{E}-13$ \\
\hline 0.90 & $5.040115785530 \mathrm{E}-01$ & $5.040115785529 \mathrm{E}-01$ & $4.274358644807 \mathrm{E}-14$ \\
\hline 1.00 & $5.150873072263 \mathrm{E}-01$ & $5.150873072265 \mathrm{E}-01$ & $1.179056852152 \mathrm{E}-13$ \\
\hline 1.10 & $5.190133197868 \mathrm{E}-01$ & $5.190133197871 \mathrm{E}-01$ & $2.902122986370 \mathrm{E}-13$ \\
\hline 1.20 & $5.166544364783 \mathrm{E}-01$ & $5.166544364787 \mathrm{E}-01$ & 4.607425552194E-13 \\
\hline 1.30 & $5.090162464214 \mathrm{E}-01$ & $5.090162464221 \mathrm{E}-01$ & $6.451505996097 \mathrm{E}-13$ \\
\hline 1.40 & 4.972489648573E-01 & $4.972489648581 \mathrm{E}-01$ & 8.351652702743E-13 \\
\hline 1.50 & $4.826498351587 \mathrm{E}-01$ & $4.826498351598 \mathrm{E}-01$ & $1.023958695612 \mathrm{E}-12$ \\
\hline 1.60 & $4.666641592316 \mathrm{E}-01$ & 4.666641592328E-01 & $1.214361944335 \mathrm{E}-12$ \\
\hline 1.70 & $4.508850642096 \mathrm{E}-01$ & $4.508850642110 \mathrm{E}-01$ & $1.404265592697 \mathrm{E}-12$ \\
\hline 1.80 & $4.370521379547 \mathrm{E}-01$ & 4.370521379563E-01 & $1.590561016229 \mathrm{E}-12$ \\
\hline 1.90 & $4.270490905788 \mathrm{E}-01$ & $4.270490905806 \mathrm{E}-01$ & $1.771249813487 \mathrm{E}-12$ \\
\hline 2.00 & 4.229006237963E-01 & 4.229006237983E-01 & $1.950384298510 \mathrm{E}-12$ \\
\hline
\end{tabular}

based on numerical differentiation are found to be absolutely stable outside some closed boundaries. We have obtained the solution by numerical differentiation methods which are derived in this paper and are more accurate. The absolute errors are very small.

\section{References}

[1] Bala Rama Krishna, C., Rama Chandra Rao, P.S., Vishwa Prasad Rao, S. and Nageswara Rao, B. (2013) Finite Difference Methods for the Solution of a Class of Singular Perturbation Problems. International Journal of Mathematical Sciences and Engineering Applications, 7, 411-421

[2] Eskandari, Z. and Dahaghin, M.S. (2012) A Special Linear Multi Step Method for Special Second Order Differenial Equations. International Journal of Pure and Applied Mathematics, 78, 1-8.

[3] Gear, C.W. (1971) Numerical Initial Value Problems in Ordinary Differential Equations. Prentice Hall, Upper Saddle River.

[4] Gragg, W.B. and Statter, H.J. (1964) Generalized Multistep Predictor-Corrector Methods. Journal of the ACM, 11, 
188-209. http://dx.doi.org/10.1145/321217.321223

[5] Henrici, P. (1962) Discrete Variable Methods in Ordinary Differential Equations. Wiley, New York.

[6] Jain, M.K. (1984) Numerical Solution of Differential Equations. Wiley Eastern Ltd., New Delhi.

[7] Kalyani, P. and Rama Chandra Rao, P.S. (2013) Solution of Boundary Value Problems by Approaching Spline Techniques. International Journal of Engineering Mathematics, 2013, Article ID: 482050.

[8] Kalyani, P. and Rama Chandra Rao, P.S. (2013) A Conventional Approach for the Solution of the Fifth Order Boundary Value Problems Using Sixth Degree Spline Functions. Applied Mathematics, 2013, 583-588.

[9] Rama Chandra Rao, P.S. (2006) Special Multistep Methods Based on Numerical Differentiation for Solving the Initial Value Problem. Applied Mathematics and Computation, 181, 500-510. http://dx.doi.org/10.1016/j.amc.2005.12.063 
Scientific Research Publishing (SCIRP) is one of the largest Open Access journal publishers. It is currently publishing more than 200 open access, online, peer-reviewed journals covering a wide range of academic disciplines. SCIRP serves the worldwide academic communities and contributes to the progress and application of science with its publication.

Other selected journals from SCIRP are listed as below. Submit your manuscript to us via either submit@scirp.org or Online Submission Portal.
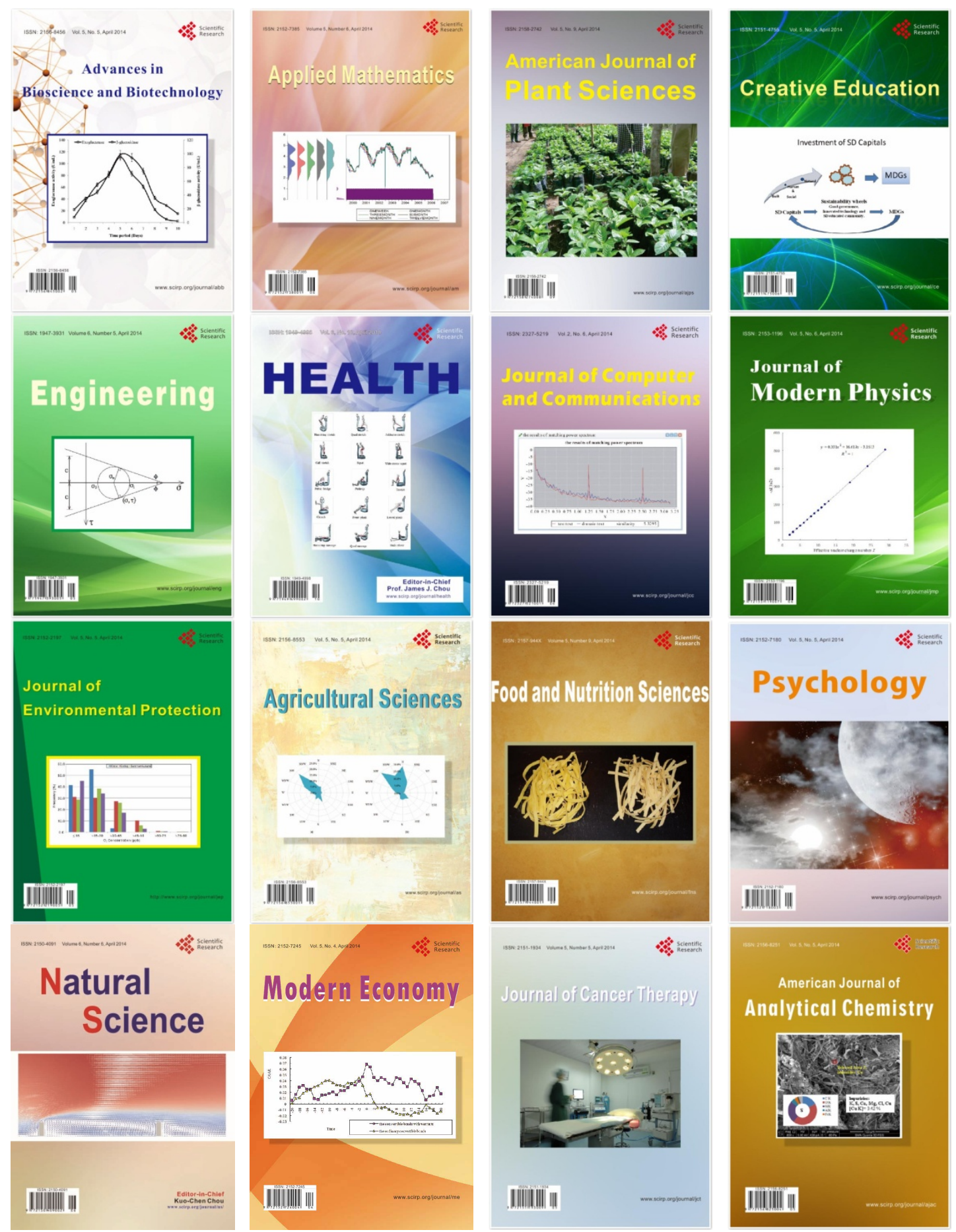